\title{
Experimental Research of Piece-Mold Casting: Gilt-Bronze Pensive Bodhisattva
}

\author{
Yong-Hyun Yun ${ }^{1, *}$, Nam-Chul $\mathrm{Cho}^{2}$, Jung-Mann Doh ${ }^{3}$ \\ ${ }^{1}$ Exhibition Division, National Science Museum, Daejeon 34143, Korea \\ ${ }^{2}$ Department of Cultural Heritage Conservation Science, Kongju National University, Gongju 32588, Korea \\ ${ }^{3}$ Interface Control Research Center, Institute of Science and Technology, Seoul 02792, Korea
}

\author{
Received July 30, 2021 \\ Revised August 5, 2021 \\ Accepted August 9, 2021 \\ *Corresponding author \\ E-mail: yh-yun@hanmail.net \\ Phone: +82-42-601-8030 \\ Journal of Conservation Science \\ 2021;37(4):340-356 \\ https://doi.org/10.12654/JCS.2021. \\ 37.4 .03 \\ pISSN: 1225-5459, eISSN: 2287-9781 \\ (C) The Korean Society of \\ Conservation Science for Cultural \\ Heritage \\ This is an Open-Access article distributed \\ under the terms of the Creative \\ Commons Attribution Non-Commercial \\ License (http://creativecommons.org/ \\ licenses/by-nc/3.0) which permits \\ unrestricted non-commercial use, \\ distribution, and reproduction in any \\ medium, provided the original work is \\ properly cited.
}

ABSTRACT We have tried the experimental research of lost-wax casting to reconstruct Gilt-Bronze Pensive Bodhisattva; preliminary and reconstruction experiment based on ancient texts. Main object to reconstruct is Korean National Treasure No.83, Gilt-Bronze Pensive Bodhisattva (Maitreya), then we measure alloy ratio and casting method based on the scientific analysis. Other impurities were removed from the base metal components(copper : tin : lead) and their ratio was set to $95.5: 6.5: 3$ where the ratios for tin and lead were increased by $2.5 \%$ each. The piece-mold casting method was used, and piece-mold casting experiments were carried out twice in this study but supplementary research on piece-mold casting was necessary.

The microstructure was confirmed to be typical cast microstructure and the component analysis result was similar to that of the prior study. Analysis of the chemical composition is confirmed to copper, tin, lead, and zinc, and the chemical composition of the matrix was $87.8 \% \mathrm{Cu}-7.5 \% \mathrm{Sn}-2.7 \% \mathrm{~Pb}-2.1 \% \mathrm{Zn}$, and similar to previous experimental research. Also resulted in the detection of small impurity in $\mathrm{Zn}$. Analysis of the mould revealed that the mould was fabricated by adding quartz and organic matter for structural stability, fire resistance, and air permeability. We expect that our research will contribute to provide base data for advanced researches in future.

Key Words Gilt-Bronze Pensive Bodhisattva (Maitreya), Piece-Mold casting, Experimental research, Microstructure, Component analysis

\section{INTRODUCTION}

Artifacts of various materials have been discovered, but among them, gilt-bronze artifacts are rare, making them that much more important. In the case of plated artifacts, the artifacts are preserved in conditions where the gold has peeled off and the copper or bronze base material are exposed, so there are scientific and technological limitations to the exhibition and protection of relics that retain the uniqueness of Korea.

Also, although a vast number of metallic artifacts was excavated, only research from natural sciences and metallurgical perspectives are carried out for such excavated metallic artifacts. Research is lacking on the smelting and alloys necessary for the traditional casting of copper based metallic artifacts including bronze and brass as well as restoration and reconstruction technologies. With regard to research on the Pensive Bodhisattva, it is mostly focused on the production period, style, and iconography of Buddhist sculptures, so research on the manufacturing method is at an elementary stage, resulting in a lack of research materials and historical records. Especially, scientific and technological research on the advanced casting and manufacturing techniques that support the half-crossed leg posture and the structure and formativeness of the Pensive Bodhisattva is necessary (Yun, 2013). 
Therefore, in this study, restoration was carried out on the bronze Pensive Bodhisattva for the National Treasure No.83 Gilt-Bronze Pensive Maitreya. This national treasure exhibits outstanding casting technology from the consistently thin thickness of the bronze metallic base layer and this artifact is considered one of the most representative Buddhist sculptures of East Asia. Thus, based on these aspects, reconstruction or reproduction experiments were conducted to investigate the traditional science and technology through the verification and reinterpretation using modern day analysis o the material characteristics, casting technique, and manufacturing technique. Moreover, the cast was reproduced based on the excavated artifact and historical records in order to reproduce the traditional casting and processing techniques (Min, 2016).

This study is expected to contribute to the establishment of protective systems for artifacts used in education and exhibitions through the utilization of restorations of exhibition artifacts that retain the uniqueness of Korea and the traditional bronze smelting, casting, and processing techniques. Furthermore, the traditional casting techniques are expected to lead to the restoration of metallic relics and attain related fundamental technologies, resulting in the expansion and application of the research foundation through the convergence research of fields related to metallic cultural assets.

In addition, this study is an experimental study on the reproduction of Pensive Bodhisattva using piece-mold casting based on the experimental research of Gilt-Bronze Pensive Bodhisattva using the lost-wax casting in 2020 (Yun et al., 2020).

\section{GILT-BRONZE MAITREYA IN MEDITATION REPRODUCTION EXPERIMENT}

\subsection{Properties of Gilt-Bronze Maitreya in meditation}

The National Treasure No. 83 Gilt-Bronze Maitreya in Meditation is also referred to as three-mountain headdress (三 山冠) or tri-fold crown Pensive Bodhisattva because of the unique crown composed of 3 semicircles placed on top of the head. This artifact and the National Treasure No. 78 Gilt-Bronze Maitreya in Meditation of similar size are the most highly regarded and representative Buddhist sculpture artworks of Korea. So, restoration reproduction experiments of these artifacts were conducted (National Museum of Korea, 2017).

The crown on the National Treasure No. 83 Gilt-Bronze Maitreya in Meditation is in the mould of 3 semicircles connected together, and this crown is simple with no other decorations on the surface but makes a strong impression. The style of this crown is very unusual and distinctive compared to those of other countries like India and China, and this style can only be found in the Pensive Bodhisattva of the old Silla region.

The manufacturing technique and the associated characteristics of the National Treasure No. 83 Gilt-Bronze Maitreya in Meditation were examined through scientific investigation results including the bronze alloy component analysis using visual observation, gamma ray imaging, and nondestructive analysis (National Museum of Korea, 2017).

Overall, the internal curves of the National Treasure No. 83 Gilt-Bronze Maitreya in Meditation matched the external shape, and numerous core pins were identified that maintains the distance between the internal and external clay. Inside, the soil used as the internal clay partially remained, and it was found that plant stems were cut short and added to the sandy clay, where coarse sand particles were mixed in. This was considered to be traces of using the typical wax casting method, which was employed to create the original shape for the internal clay as similarly as possible and involved sculpting with wax-coated followed by removing the wax and pouring of bronze for the casting. The head and body were made as one from the beginning without separating the internal clay, and large casting defects were not observed except for the rear lower portion of the pedestal and left foot lotus pedestal (National Museum of Korea, 2017).

The gamma ray imaging results revealed a thick rectangular iron-core internally from the head to the pedestal vertically as well as thin iron cores that crossed over like an $\mathrm{X}$ at the chest and extended into each arm. At the locations where the thick vertical iron core and the thin horizontal iron cores meet, the cores were not tied to each other and a separate string was not used but rather the thin iron cores were placed from both sides into a hole made in the thick iron core so that the thin cores crossed over like an X. The bodies of the thin iron cores that extend into each arm was 
securely fixed to the thick iron core so that defects which can occur from the movement of the internal clay in the thin arms during the casting are prevented in advance. Above the thin iron cores within the arms were wires that are wound like a thread and these wires were thought to be devices to facilitate the attachment of the sandy clay with coarse particles as the wires were not observed in the National Treasure No. 78 Gilt-Bronze Maitreya in Meditation(National Museum of Korea, 2017).

The nondestructive component analysis result showed that the main body was composed of bronze that contained about $4 \sim 5 \%$ of tin and this content is almost equivalent to that of the National Treasure No. 78 Gilt-Bronze Maitreya in Meditation main body. Measurements of the repaired areas including two areas at the bottom surface of the cylindrical chair and the front portion of the left foot on the lotus showed that the left side of the chair bottom surface and the lotus pedestal were composed of pure copper with almost no tin. Areas with components that matched the main body were determined to be areas that were repaired during the casting and the two areas repaired with pure copper were determined to have been repaired in the unified Silla period when Buddhist sculptures casted using pure copper were introduced. It was thought that all three areas were repaired during the initial casting but later on these areas had to undergo repairs again (National Museum of Korea, 2017).

\subsection{Reproduction study using piece-mold casting}

\subsubsection{External mold fabrication (Figure 1)}

A sturdy and robust mould is necessary for successful piece-mold casting. A mould made with appropriate materials and mixed together at appropriate proportions exhibits high strength and can withstand heat and pressure when molten metal is poured.

Preliminary experimentation was conducted to present a systematic methodology for the traditional casting and restoration technologies of the bronze Pensive Bodhisattva. Utilizing preceding materials, the cast was made with piece-mold and molten metal was poured in followed by a series of refinements to successfully restore a $1 / 3$ scale model of the bronze Pensive Bodhisattva. Based on these results, a $1 / 2$ scale of the Pensive Bodhisattva was cast.
First, a 1/2 scale plaster model of the pensive bodhisattva is prepared. After sprinkling charcoal powder on the bottom surface, loess is applied in a thick manner. The surface is then polished with a burin followed by attaching wet hanji. This is done so that when loess is applied to the top surface in the mould fabrication process, they do not stick to each other.

After attaching the hanji, a soil mixture is prepared to fabricate the partial molds. The head, right hand, feet, and waist of the plaster model are small and are at risk of cracks, so the soil mixture is applied to these areas. Here, the soil mixture contains $515 \mathrm{~g}$ of loess, $200 \mathrm{~g}$ of kaolin, $200 \mathrm{~g}$ of heat treated sand, $50 \mathrm{~g}$ of charcoal powder, and $35 \mathrm{~g}$ of hanji soaked in water (1 kg soil mixture basis). This soil mixture is used rather than loess because it is more effective at replicate the expression details. Once the soil mixture is applied, wet hanji is then applied similarly.

Afterwards, the soil mixture is rolled over to have a thickness of $3 \sim 4 \mathrm{~mm}$ over the entire figure. Then, a brush is used to closely adhere the soil mixture. Loess is then applied again and thick rods are placed after criss crossing them in a \# pattern. Next, rough soil is prepared and applied in a thick manner. The rough soil is prepared with $730 \mathrm{~g}$ of loess, $100 \mathrm{~g}$ of kaolin, $60 \mathrm{~g}$ of rice husk, $80 \mathrm{~g}$ of straw and $30 \mathrm{~g}$ of hanji (1 $\mathrm{kg}$ rough soil basis). All the steps up to now have to be carried out after sufficient natural drying.

Now, fabrication of the front mould is complete and the rear mould is fabricated following the same procedure after $2 \sim 3$ days of drying. Following this, drying is carried out for around 1 day in a kiln or heating chamber.

\subsubsection{Mould supplementation (Figure 2)}

When the basic work on the front and rear sides of the mould is completed, it is dried for around 24 hours in a kiln at a temperature of around $100 \sim 150^{\circ} \mathrm{C}$. After sufficient drying, the partial molds within the mould have to be polished and attached. In this process, a sharp and acute tool such as a burin or a wooden stick has to be used to carefully remove the partial molds without damaging them. Areas with detailed expressions like the ends of the dress are made sure to preserve the shapes and parts that have fallen off are filled up or plugged with soil. When all the supplementary work is done, the needles applied for fixture are removed and water is used for adhesion to the mould. 


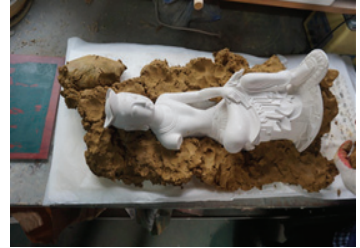

A

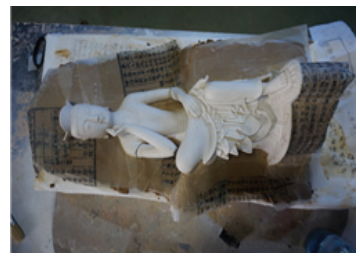

D

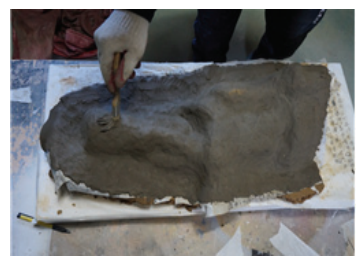

$\mathbf{G}$

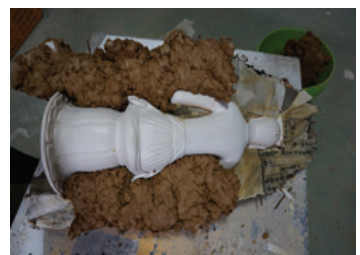

J

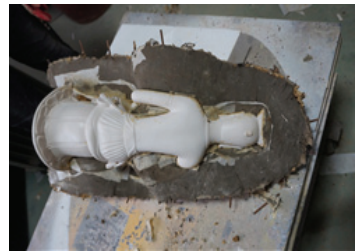

M

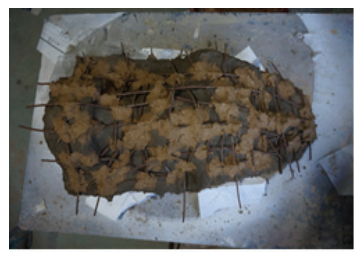

P

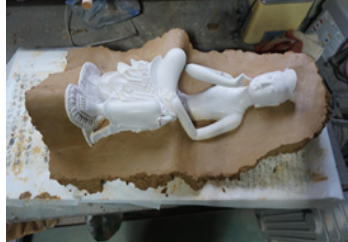

B

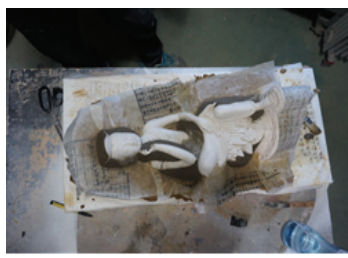

E

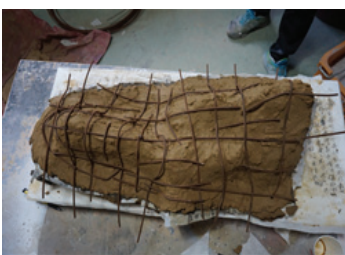

H

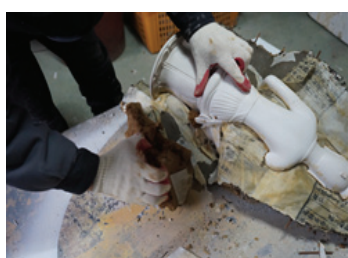

K

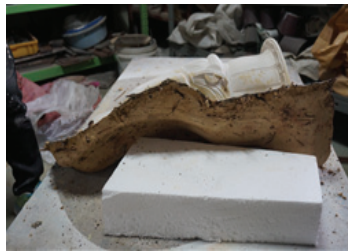

$\mathbf{N}$

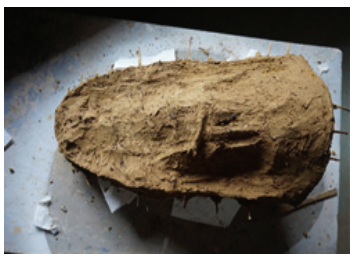

$\mathbf{Q}$

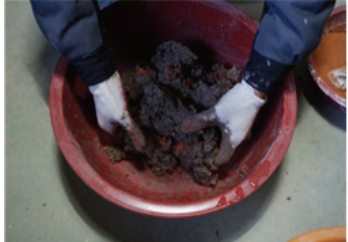

C

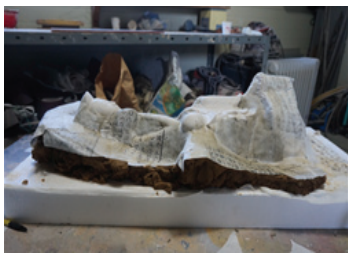

F

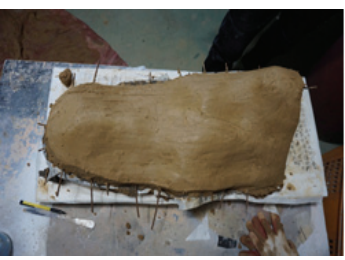

I

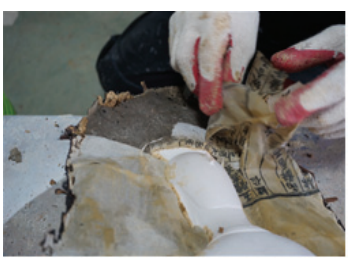

$\mathbf{L}$

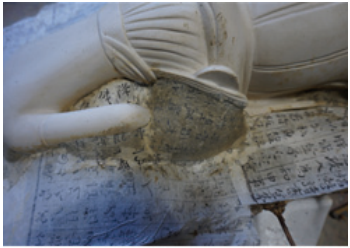

$\mathbf{O}$

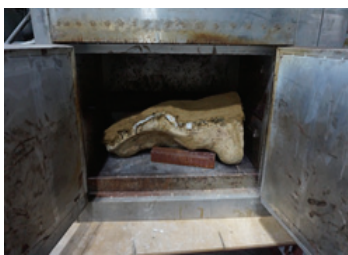

$\mathbf{R}$

Figure 1. Reproduction study using piece-mold casting (Experiment 1). (A) Attach loess on the bottom surface of the plaster model. (B) Polish the surfaces smooth. (C) Prepare the soil mixture. (D) Apply hanji to the surface. (E) Fabrication of the partial molds after applying the soil mixture. (F) Apply hanji to the partial molds(soil mixture). (G) Apply thinly flattened soil mixture. (H) Place loess over and reinforce with twisted rods. (I) Finish by placing the rough soil over in a thick manner. (J) Flip over the mould. (K) Remove the loess. (L) Remove the hanji. (M) After removing the hanji and loess. (N) After removing the hanji and loess. (O) Apply the soil mixture and hanji. (P) Thinly flatten the paper clay and reinforce with rods. (Q) Cover with loess. (R) Place in a kiln and dry. 


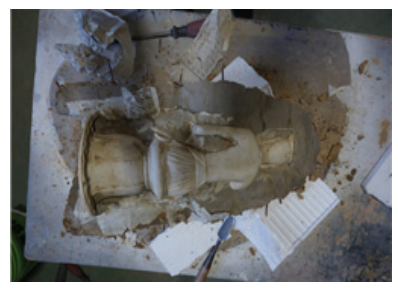

A

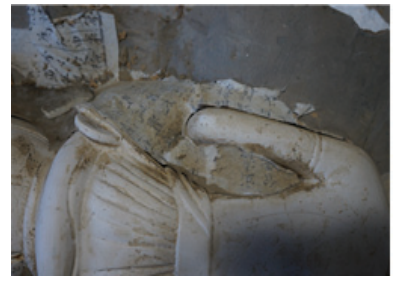

D

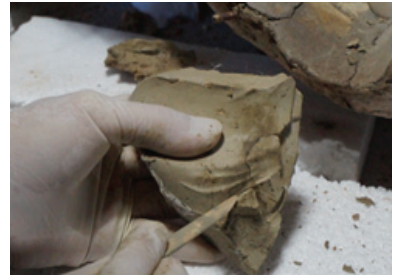

G

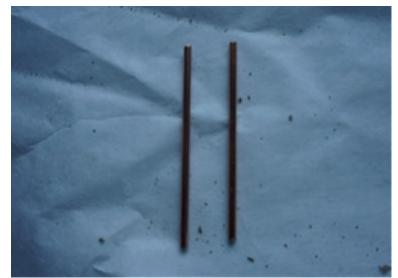

J

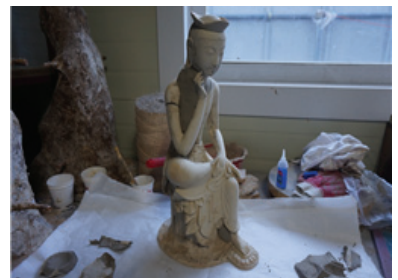

M

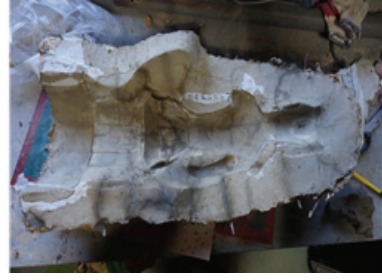

B

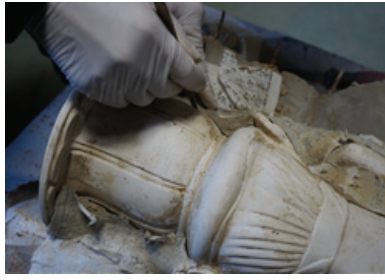

E

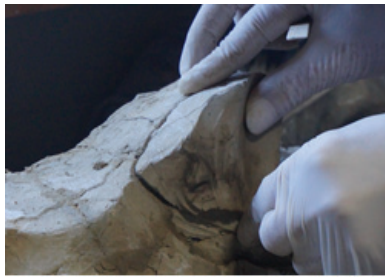

H

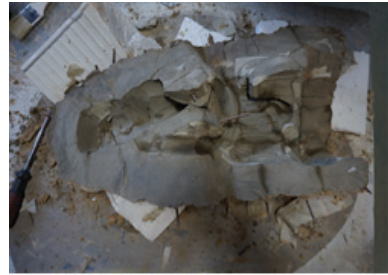

K

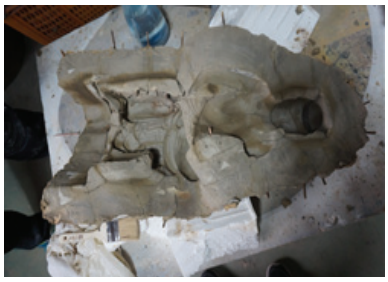

N

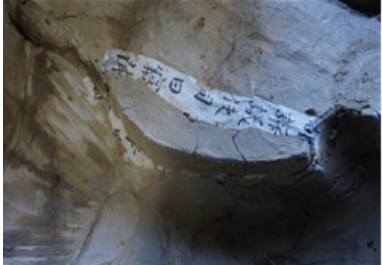

C

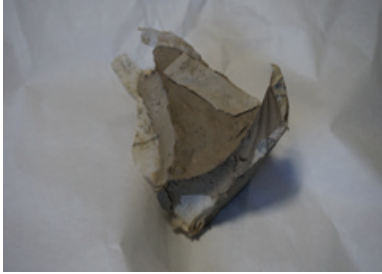

F

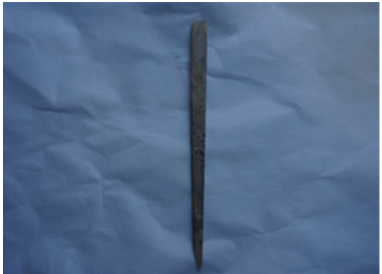

I

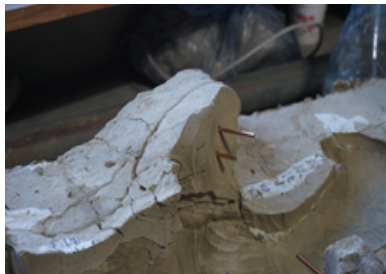

L

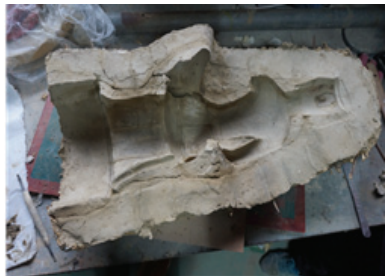

O

Figure 2. Mould supplementation. (A) Front side mould Separated mould. (B) Separated mould(rear) (C) dried partial molds (1). (D) Dried partial molds (2). (E) Partial molds separation. (F) Separated partial molds. (G) Partial mold shape polishing. (H) Try fitting in place. (I) Wooden stick. (J) Needles. (K) Front side mould fixed using pins. (L) Back side mould fixed using pins. (M) Front side mould original shape separated from the mould. (N, O) Front side mould supplementary process completed mould.

\subsubsection{Core fabrication (Figure 3)}

A separate mold is fabricated to create an empty space for the molten metal in the casting to be poured into. This is called the core.
The following is the fabrication process. First, clay is thinly flattened to a thickness of $4 \sim 5 \mathrm{~mm}$ and then adhered within the mould. Wet hanji is attached on top of this. Next, 


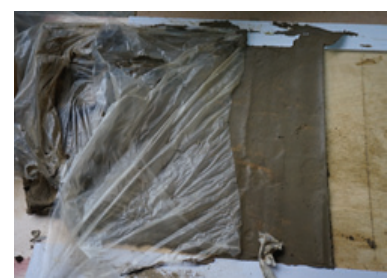

A

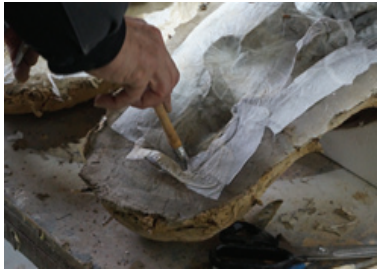

D

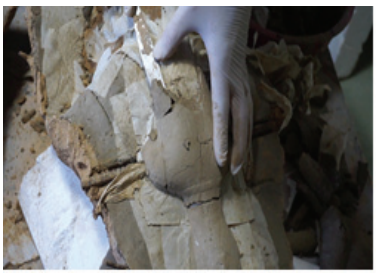

G

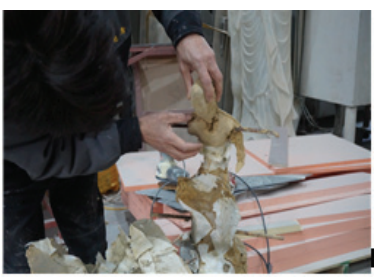

$\mathbf{J}$

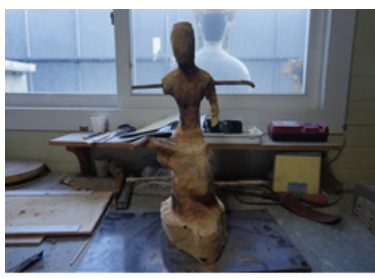

M

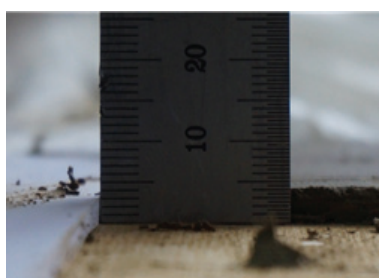

$\mathbf{B}$

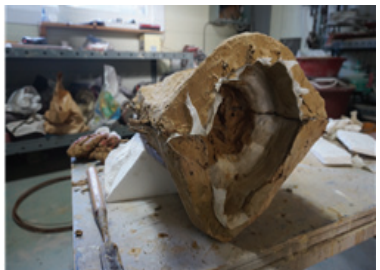

$\mathbf{E}$

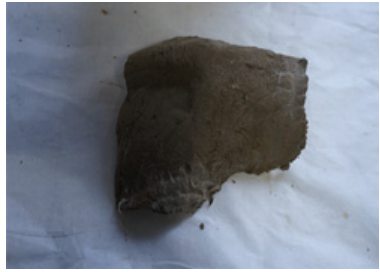

$\mathbf{H}$

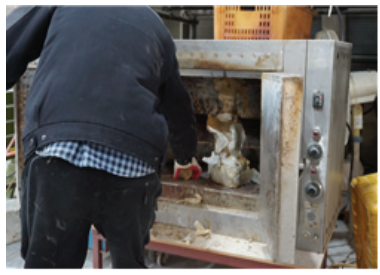

$\mathbf{K}$

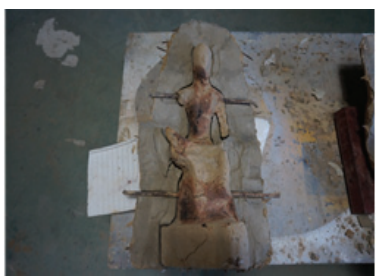

$\mathbf{N}$

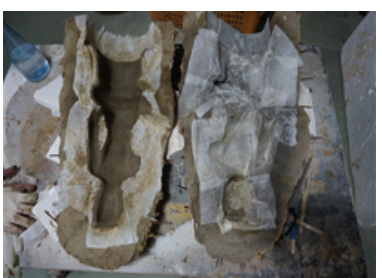

C

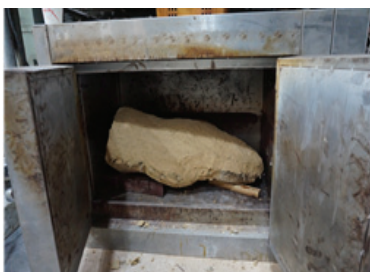

$\mathbf{F}$

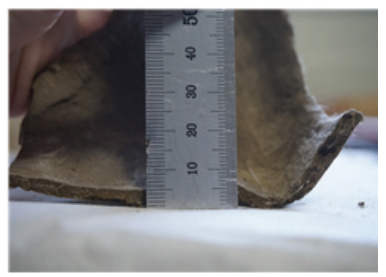

I

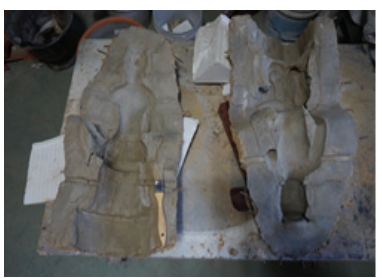

$\mathbf{L}$

Figure 3. Core Fabrication. (A) Thinly flattened clay. (B) Clay thickness. (C) Clay and hanji adhesion to the mould. (D) Applying hanji. (E) Filling the mould interior with loess. (F) Drying in a kiln. (G) Removal of the thin clay. (H) Removed thin clay. (I) Thickness of the removed thin clay (molten metal thickness). (J) Core separation. (K) Drying in a kiln. (L) Mould with all the thin clay removed. (M) Completed core. (N) Fit the core in place.

the front and rear sides of the mould are joined together and the interior is meticulously filled with loess. Afterwards, it is placed in a kiln and dried for approximately $1 \sim 2$ hours. After sufficient drying, the thin clay adhered within the core and mould dries and a sharp tool is used to remove all of the clay. The empty space produced from this process is called a cavity where the molten metal will enter. The molten metal thickness is the same $4 \sim 5 \mathrm{~mm}$ as that of the clay thickness and there are thicker parts depending on the area such as the knees. The completed core is then inserted within the mould. 


\subsubsection{Mould assembly and molten metal preparation} (Figure 4)

Before pouring the molten metal, the mould is dried again and the front and rear are joined together to be wrapped using a wire. The mould has to be strongly reinforced for it to withstand the pressure of the molten metal.

The process of preparing the molten metal to be poured into the mould is necessary. The bronze casting component ratios of this process was set to $95.5: 6.5: 3$ (copper : tin : lead) where the impurities were removed from the base metal components and the tin and lead proportions were increased by $2.5 \%$ each. However, the fact that the casting component could decrease with increasing molten metal time due to the low melting point was taken into consideration. In this process, ingots were melted and used as the molten metal in accordance with the casting components as metal is melted and solidified to make ingots (Yun et al., 2019).

\subsubsection{Molten metal injection, mould disassembly, abrasion polishing (Figure 5)}

Before pouring the molten metal, the molten metal inlet was made on the mould with soil as shown in Figure 5(B). After melting the molten metal for approximately $1 \sim 2$ hours, it was poured into a crucible and then poured into the mould. In the injection process, a small amount of the molten metal leaked to the side of the mould. It was assumed that the leak was located between the reinforcing bar on the core and the piece-mold mould gap, but a follow-up study is necessary. The molten metal was injected over 2 pouring sessions and the injection was completed.

After $1 \sim 2$ hours after the pouring of the molten metal, the reinforcing bar and mould were disassembled. Inspection of the surface revealed that there were areas that the molten metal did not reach. The lower part of the face, the back of the head, and the ends of the dress were areas that their shapes were not expressed. Also, although the front part is acceptable, the rear part surface was uneven, resulting in dents. The causes behind these results were, first, that the core shook in the process of moving it to the casting site, second, problems with the soil, firing temperature, and number of times for steps in the mould fabrication process, and third, problems with the separation parts and the number of those parts for the piece-mold mould. Solutions to the above issues will be addressed and the piece-mold mould process will be carried out again. The casting fabricated in this experiment was completed with a primary polishing using a hammer and chisel. Th finished Pensive Bodhisattva did not flow smoothly, and there were many casting defects (Figure $5(\mathrm{M})$ ). Figure $5(\mathrm{~N})$ shows the results of a second experiment with a similar process and a more complete Pensive Bodhisattva compared to the first experiment.

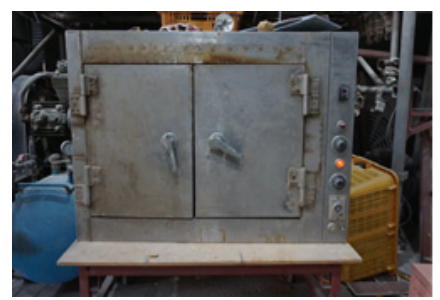

A

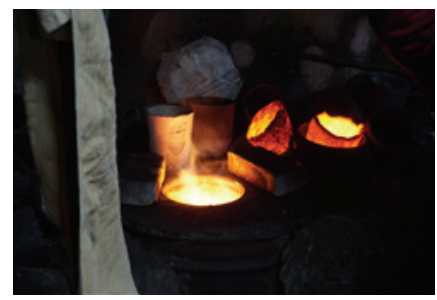

D

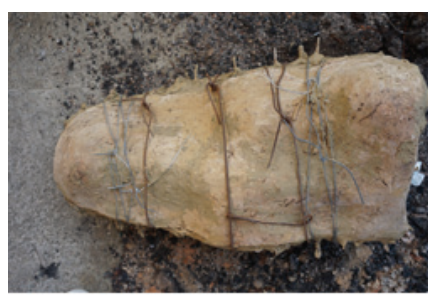

B

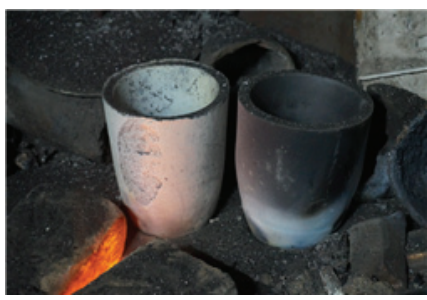

$\mathbf{E}$

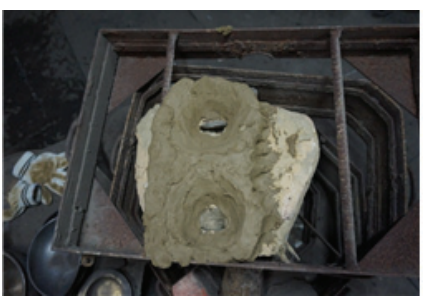

C

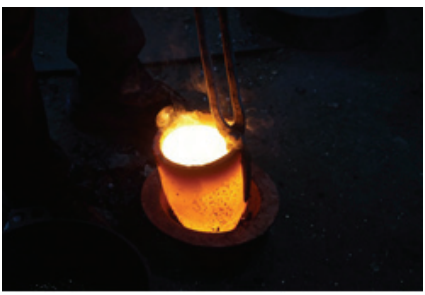

$\mathbf{F}$

Figure 4. Mould assembly and molten metal preparation. (A) Drying in a kiln. (B) Tie the mould together with a wire. (C) Fabricate the molten metal inlet. (D) Blast furnace. (E) Crucible. (F) Molten metal. 


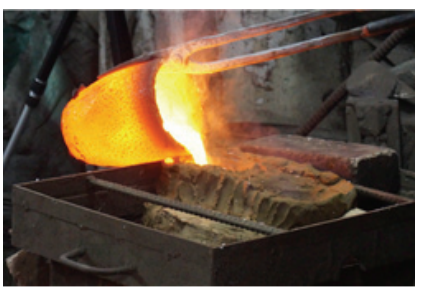

A

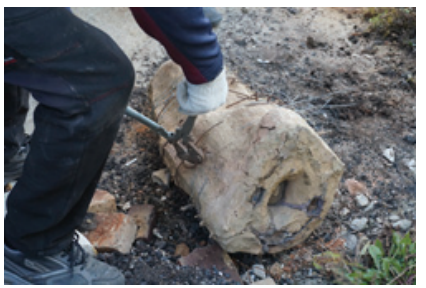

D

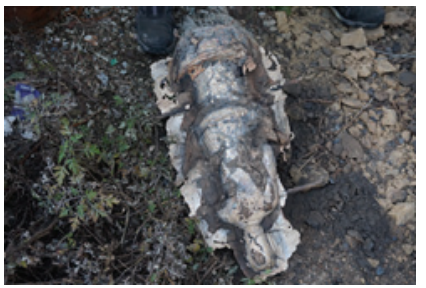

G

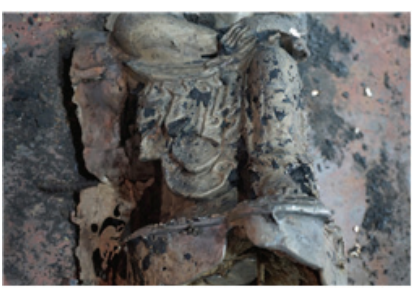

$\mathbf{J}$

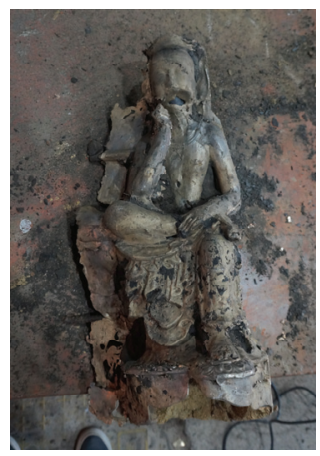

M

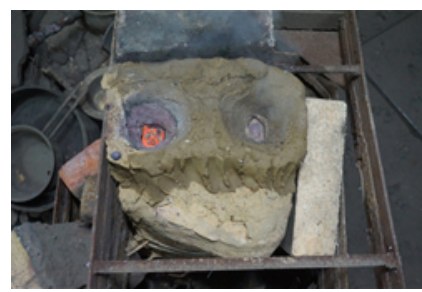

B

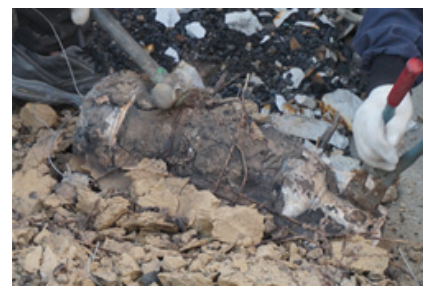

$\mathbf{E}$

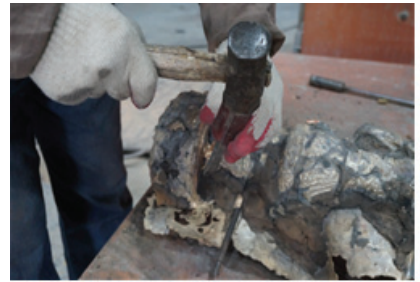

H

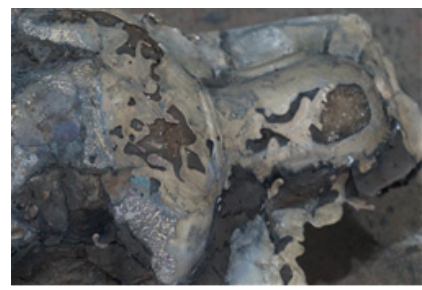

K

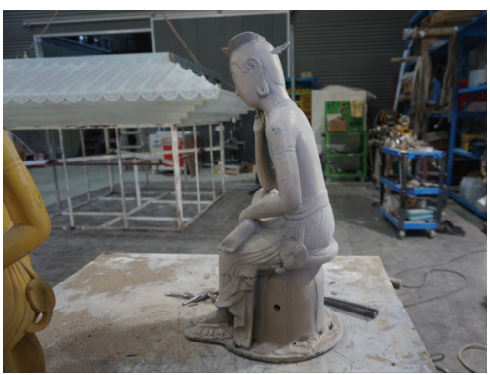

N

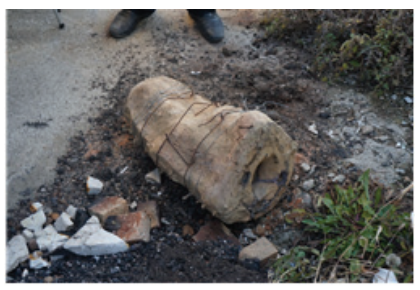

C

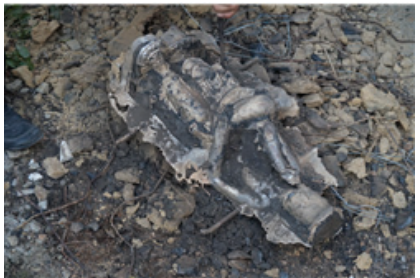

F

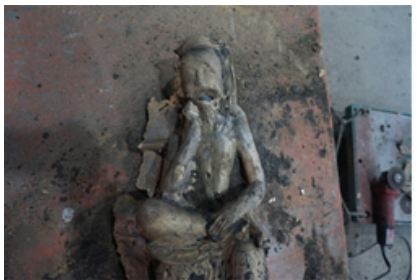

I

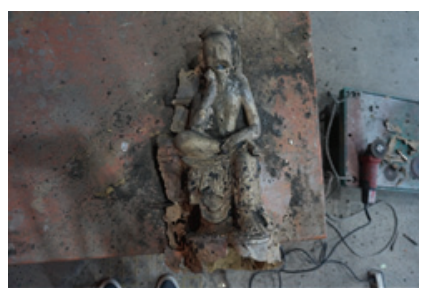

$\mathbf{L}$

Figure 5. Molten metal injection, mould disassembly, abrasion polishing. (A) Molten metal injection. (B) After molten metal injection. (C) Cooled mould after injection, (D) Reinforcing bar disassembly. (E) Mould disassembly using a hammer. (F) Disassembled mould (front). (G) Disassembled mould (back). (H) Polishing. (I) Casting with mould disassembly complete (top). (J) Casting with mould disassembly complete (bottom). (K) Casting with mould disassembly complete (head). (L) Casting with mould disassembly complete (front). (M) After complete dismantling of the mould. (N) Pensive Bodhisattva completed after the second experiment. 


\section{SCIENTIFIC ANALYSIS}

\subsection{Analysis subject}

\subsubsection{Gilt-Bronze Pensive Bodhisattva related pedestal pathway}

In order to analyze the microstructure and chemical composition of the Gilt-Bronze Pensive Bodhisattva cast using piece-mold casting, 2 small ingots (head pathway, pedestal pathway) were extracted after casting the pensive bodhisattva. Figure 6 shows a small ingots pedestal pathway and a specimen extract areas.

\subsubsection{Gilt-Bronze Pensive Bodhisattva mould}

Gilt-Bronze Pensive Bodhisattva moulds produced curing casting were collected and used for analysis. Figure 7 is a pre-analyzed image of a mould, organic matter was observed in all specimens where $4 \sim 5$ layers are observed depending on whether the specimen was from the exterior or interior.

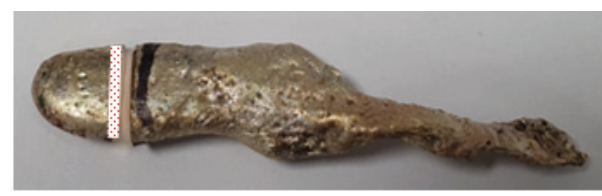

A

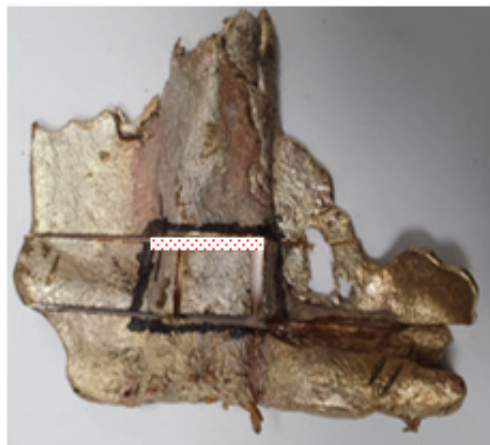

B

Figure 6. A macroscopic image of sample Gilt-Bronze Pensive Bodhisattva. (A) Head pathway. (B) Pedestal pathway.

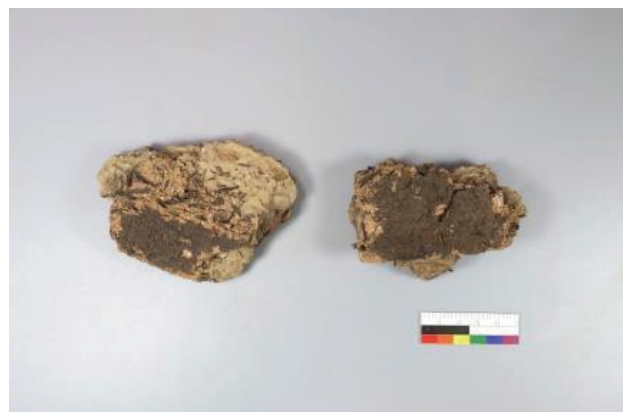

A

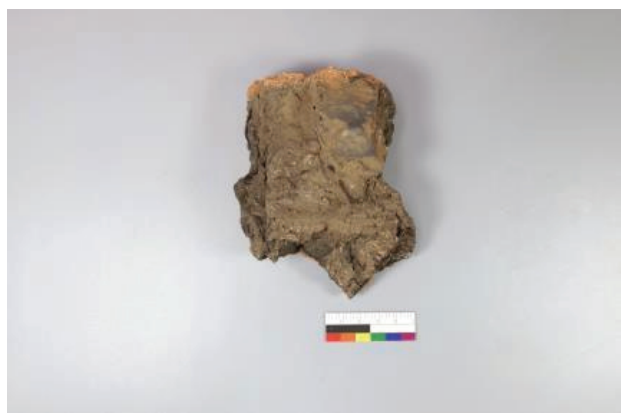

C

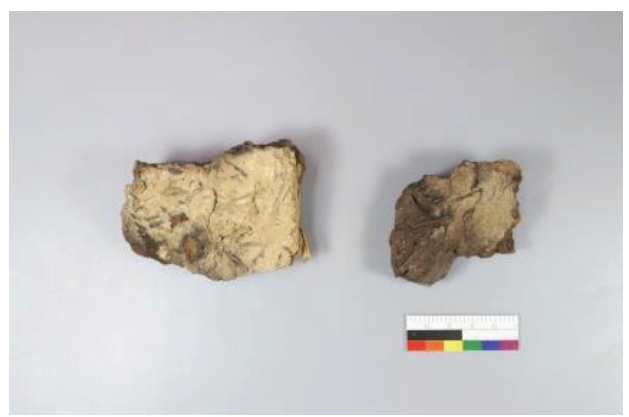

B

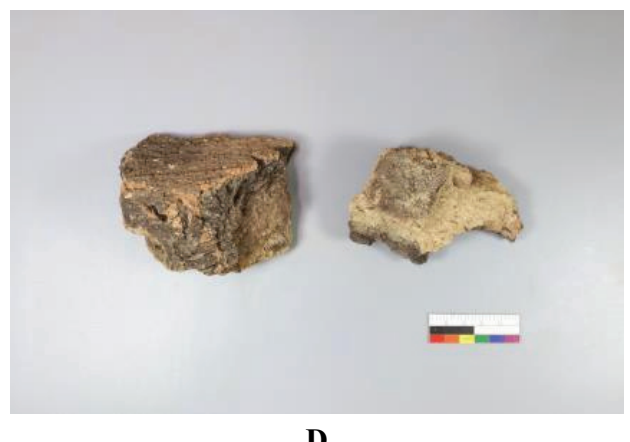

D

Figure 7. Image of the mould specimen before analysis. (A) No. 1 rear buttocks. (B) No. 2 pedestal knee. (C) No. 3 rear head. (D) No. 4 knee. 


\subsection{Analysis method}

\subsubsection{Pedestal pathway of Gilt-Bronze Pensive Bodhisattva}

The extracted ingots were cut into appropriate sizes, placed in mounting resin, and polished. In order to observe the microstructure and quantify the chemical composition of the pensive bodhisattva, the specimens were polished using $0.05 \mu \mathrm{m}$ diamond paste . After observing the microstructure of the bronze specimen using EPMA, the chemical composition of the desired area was quantified. The entire composition of the bronze was quantified using a $300 \mu \mathrm{m}$ diameter beam size and then the composition of smaller areas(white area, light gray area, gray area, dark gray area) were quantified by reducing the beam size to $1 \mu \mathrm{m}$. Figure 6 shows a macroscopic image of the cut locations and observation surfaces of the Gilt-Bronze Pensive Bodhisattva casting bronze specimens used in the microstructure and composition analysis.

\subsubsection{Gilt-Bronze Pensive Bodhisattva mould}

Before the analysis, the exterior and interior specimens were distinguished, then ground into an appropriate size. The 4 specimens pertaining to the rear head and knee were too large for mounting so they underwent powdering by layer followed by principal component and compound analyses. The rear buttocks and pedestal knee were mounted and their microstructures were observed (Table 1). For the principal component analysis, ultrasonic cleaning was carried out for the specimens and then the dried specimens were pulverized. The principal component analysis was conducted using a wavelength dispersive X-ray fluorescence spectrometer. The specimens were vitrified through pretreatment, and the analysis result was measured and shown through semi-quantitative analysis.

For the microstructure observation, mounting was done using epoxy resin to observe the specimen cross section. For mould 1, the exterior and interior were mounted separately, but for mould 2, the exterior and interior were distinguishable even with one specimen so only one specimen was extracted and mounted. The mounted specimen was sequentially polished from 100 mesh up to 4000 mesh followed by micropolishing using $3 \mu \mathrm{m}$ and $1 \mu \mathrm{m}$ until there were no scratches on the specimen. Afterwards, the microstructure of the specimen was observed using a metallographic microscope. A scanning electron microscope was used to observe the detailed microstructure and an energy dispersive X-ray spectrometer was used to analyze the chemical composition of the microstructure. The analysis specimens were coated with platinum $(\mathrm{Pt})$ to increase the specimen conductivity and minimize the effect on the composition ratio.

\subsection{Alloy specimen analysis results}

\subsubsection{EPMA analysis result}

Figure 8 shows the scanning electron microscope back scattered electron (BSE) image and EPMA analysis location of the head pathway bronze specimen. The microstructure of the Gilt-Bronze Pensive Bodhisattva exhibited the typical cast microstructure. Figures 8 (A), (B), and (C) show the 100x, $500 \mathrm{x}, 1000 \mathrm{x}$ magnification BSE images and (D) shows the micro-composition analysis locations $(2,3,4,5,6,7)$.

White and light gray precipitate phases and vacancies were observed within the base material (bright areas + dark areas) in the microstructure of the Gilt-Bronze Pensive Bodhisattva. Table 2 shows the chemical composition analysis result of the matrix structure and the precipitate phases dispersed within the matrix structure. The Gilt-Bronze Pensive Bodhisattva is composed of copper, tin, lead, and zinc, and the chemical composition (weight ratio) of the matrix was $87.8 \% \mathrm{Cu}-7.3 \% \mathrm{Sn}-2.7 \% \mathrm{~Pb}-2.1 \% \mathrm{Zn}$. The chemical composition(weight ratio) of the white precipitate phase(location 2) within the matrix structure was $93.9 \% \mathrm{~Pb}$ $-6.1 \% \mathrm{Cu}$ so it was determined to be lead particles. The chemical composition (weight ratio) of the bright gray

Table 1. Analysis method

\begin{tabular}{l|c|c|c|c}
\hline & WD-XRF & XRD & $\begin{array}{c}\text { Metallographic } \\
\text { microscope }\end{array}$ & SEM-EDS \\
\hline No. 1 rear buttocks & & & 0 & 0 \\
\hline No. 2 pedestal knee & & & 0 & 0 \\
\hline No. 3 the rear head & 0 & 0 & & \\
\hline No. 4 knee & 0 & 0 & & \\
\hline
\end{tabular}




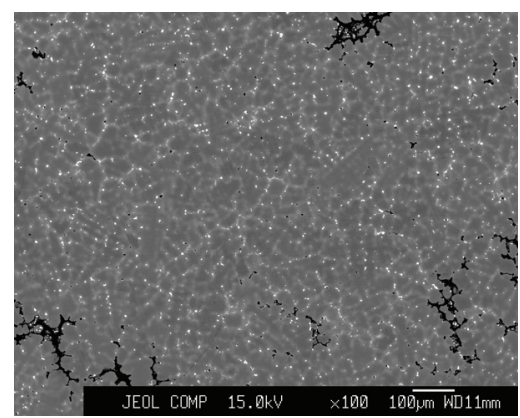

A

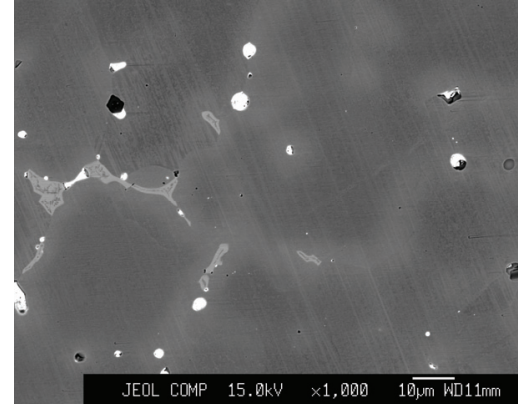

C

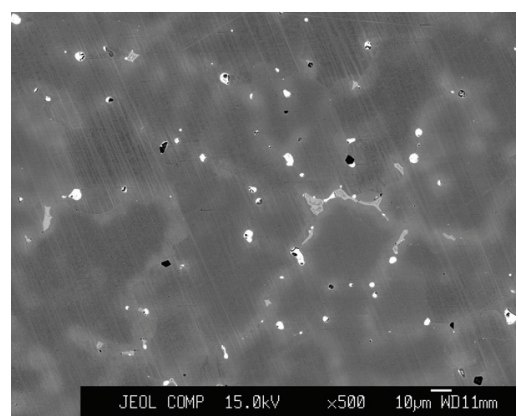

B

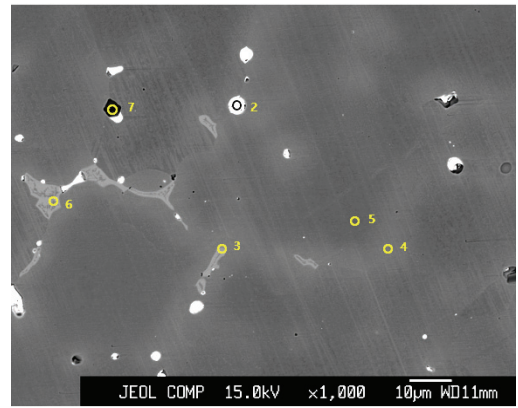

D

Figure 8. The scanning electron microscope back scattered electron (BSE) image location of the head pathway bronze specimen. (A) 100x. (B) 500x. (C) 1000x. (D) The micro-composition analysis locations (2, 3, 4, 5, 6, 7).

Table 2. EPMA analysis result location of the head pathway (Unit: wt $\%$ (at $\%)$ )

\begin{tabular}{|c|c|c|c|c|c|c|}
\hline Comp. & total & 2 & 3 & 4 & 5 & 6 \\
\hline $\mathrm{Cu}$ & $87.8(92.8)$ & 6.1(17.6) & $69.2(80.7)$ & $87.5(92.1)$ & $95.5(96.5)$ & $72.4(82.6)$ \\
\hline $\mathrm{Sn}$ & $7.5(4.3)$ & - & $30.8(19.3)$ & $10.6(6.0)$ & $2.0(1.1)$ & $26.6(16.3)$ \\
\hline $\mathrm{Pb}$ & $2.7(0.9)$ & $93.9(82.4)$ & - & - & - & - \\
\hline $\mathrm{Zn}$ & $2.1(2.1)$ & - & - & $1.9(1.9)$ & $2.5(2.4)$ & $1.0(1.1)$ \\
\hline Phase & $a-C u+\delta$ & $\mathrm{Pb}$ & $\delta$ & $\begin{array}{c}\mathrm{a}-\mathrm{Cu} \\
\text { (high temp.) }\end{array}$ & $\begin{array}{c}\mathrm{a}-\mathrm{Cu} \\
\text { (low temp.) }\end{array}$ & $\begin{array}{c}\text { Eutectoid } \\
(\mathrm{a}-\mathrm{Cu}+\delta)\end{array}$ \\
\hline
\end{tabular}

phase(location 3) produced in the grain boundary was composed of the $\delta$ phase with copper and tin contents of $69.2 \% \mathrm{Cu}-30.8 \% \mathrm{Sn}$. The matrix structure was composed as a mixedstructure of the bright (location 4) areas and dark(location 5) areas. The chemical composition (weight ratio) of the bright areas and dark areas were $87.5 \% \mathrm{Cu}$ $10.6 \% \mathrm{Sn}-1.9 \% \mathrm{Zn}$ and $95.5 \% \mathrm{Cu}-2.0 \% \mathrm{Sn}-2.5 \% \mathrm{Zn}$, respectively. The tin concentration of the bright areas was around $8.6 \%$ greater than that of the dark areas. Also, the chemical composition of the eutectoid structure (location 6) produced in the grain boundary was $72.4 \% \mathrm{Cu}-26.6 \% \mathrm{Sn}-1.0 \% \mathrm{Zn}$ while the chemical composition of the black (location 7) areas was found to be $\mathrm{MnS}$ (46.6\%Mn-35.2\%S-1.2Cr\%-1.3\% $\mathrm{Fe}-$ $7.0 \% \mathrm{Cu}-8.7 \% \mathrm{Zn}$ ) with small contents of iron, zinc, and chrome.

Figure 9 shows the scanning electron microscope BSE image and EPMA analysis location of the pedestal pathway bronze specimen. The microstructure of the Gilt-Bronze Pensive Bodhisattva exhibited the typical cast microstructure. Figures 9 (A), (B), and (C) show the 100x, 500x, 1000x magnification BSE images and (D) shows the microcomposition analysis locations $(2,3,4,5,6,7)$. 
White and light gray precipitate phases and vacancies were observed within the base material(bright areas + dark areas) in the microstructure of the Gilt-Bronze Pensive Bodhisattva. Table 3 shows the chemical composition analysis result of the matrix structure and the precipitate phases dispersed within the matrix structure. The Gilt-Bronze Pensive Bodhisattva is composed of copper, tin, lead, and zinc, and the chemical composition of the matrix was $87.8 \% \mathrm{Cu}-7.5 \% \mathrm{Sn}-2.7 \% \mathrm{~Pb}-2.1 \% \mathrm{Zn}$. The chemical composition (weight ratio) of the white precipitate phase (location 2) within the matrix structure was $93.8 \% \mathrm{~Pb}-6.2 \% \mathrm{Cu}$ so it was

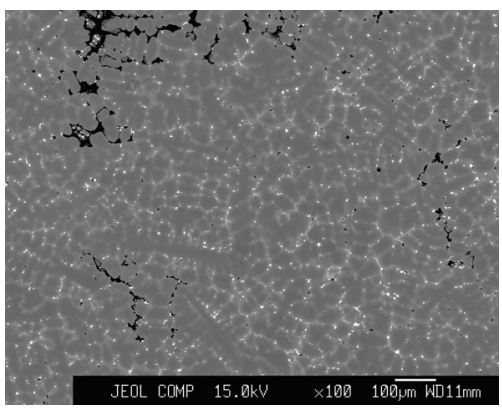

A

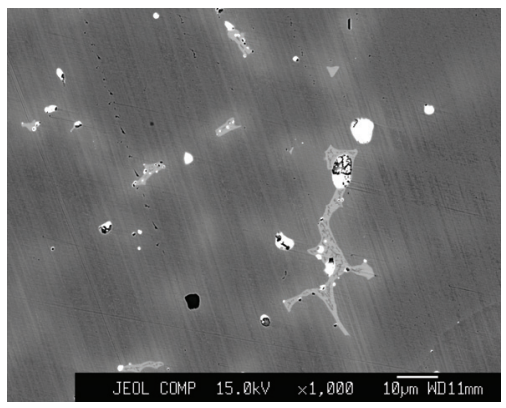

C determined to be lead particles. The chemical composition (weight ratio) of the bright gray phase (location 3) produced in the grain boundary was composed of the $\delta$ phase with copper and tin compositions of $65.7 \% \mathrm{Cu}-34.3 \% \mathrm{Sn}$. The matrix structure was composed as a mixed structure of the bright(location 4) areas and dark (location 5) areas. The chemical composition (weight ratio) of the bright areas and dark areas were $85.5 \% \mathrm{Cu}-12.7 \% \mathrm{Sn}-2.6 \% \mathrm{Zn}$ and $92.9 \% \mathrm{Cu}-$ $3.7 \% \mathrm{Sn}-2.6 \% \mathrm{Zn}$, respectively. The tin concentration of the bright areas was around $9.0 \%$ greater than that of the dark areas. Also, the chemical composition of the eutectoid

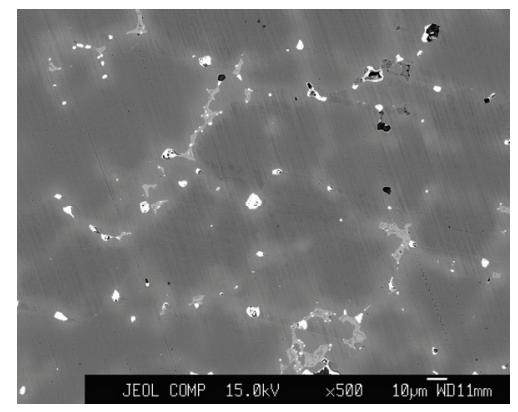

B

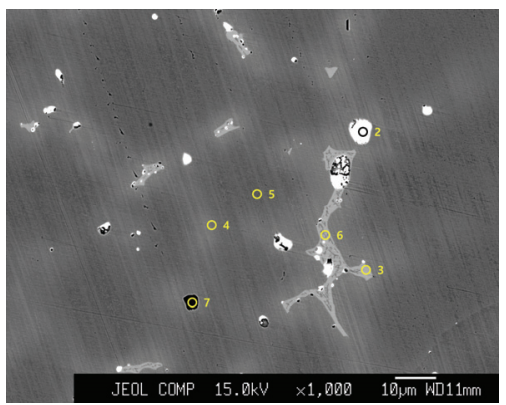

D

Figure 9. The scanning electron microscope back scattered electron (BSE) image location of the pedestal pathway bronze specimen. (A) 100x. (B) 500x. (C) 1000x. (D) the micro-composition analysis locations (2, 3, 4, 5, 6, 7).

Table 3. EPMA analysis result location of the pedestal pathway bronze specimen (Unit: $w t \%$ (at $\%)$ )

\begin{tabular}{c|c|c|c|c|c|c}
\hline & Total & $\mathbf{2}$ & $\mathbf{3}$ & $\mathbf{4}$ & $\mathbf{5}$ & $\mathbf{6}$ \\
\hline $\mathrm{Cu}$ & $87.8(92.8)$ & $6.2(17.7)$ & $65.7(78.2)$ & $85.5(91.0)$ & $92.9(95.8)$ & $72.8(82.7)$ \\
\hline $\mathrm{Sn}$ & $7.5(4.3)$ & - & $34.3(21.8)$ & $12.7(7.3)$ & $3.7(1.1)$ & $25.8(15.7)$ \\
\hline $\mathrm{Pb}$ & $2.7(0.9)$ & $93.8(82.3)$ & - & - & - & - \\
\hline $\mathrm{Zn}$ & $2.1(2.1)$ & - & - & $1.7(1.8)$ & $2.6(2.6)$ & $0.9(1.0)$ \\
\hline Phase & & $\mathrm{Pb}$ & $\delta$ & $\begin{array}{c}\mathrm{a}-\mathrm{Cu} \\
\text { (high temp. })\end{array}$ & $\begin{array}{c}\mathrm{a}-\mathrm{Cu} \\
(\text { low temp. })\end{array}$ & $\begin{array}{c}\text { Eutectoid } \\
(\mathrm{a}-\mathrm{Cu}+\delta)\end{array}$ \\
\hline
\end{tabular}


structure(location 6) produced in the grain boundary was $72.8 \% \mathrm{Cu}-25.8 \% \mathrm{Sn}-0.9 \% \mathrm{Zn}$ while the chemical composition of the black (location 7) areas was found to be $\mathrm{MnS}$ $(16.7 \% \mathrm{Mn}-32.1 \% \mathrm{~S}-1.3 \% \mathrm{Fe}-5.0 \% \mathrm{Cu}-44.9 \% \mathrm{Zn})$ with small contents of iron, zinc, and chrome.

From the comparison between the phases observed in the bronze specimen and the $\mathrm{Cu}-\mathrm{Sn}$ binary phase diagram, it was found that the Gilt-Bronze Pensive Bodhisattva exhibited a binary phase structure composed of the $\mathrm{a}-\mathrm{Cu}$ matrix phase with high copper content and $\delta(20.5$ at $\%)$ precipitate phase with high tin content. Also, a-Cu and $\delta$ phases mixed vacancies existed here and there, and $\mathrm{Pb}$ and $\mathrm{MnS}$ phases were dispersed within the matrix phase.

Meanwhile, the matrix structure was a mixture of bright and dark areas, and the tin concentration of the bright areas was $8.6 \sim 9.0 \mathrm{wt} \%(4.9 \sim 6.2 \mathrm{at} \%)$ higher than that of the dark areas. The tin concentration difference of the a-Cu phase can be predicted from the $\mathrm{Cu}-\mathrm{Sn}$ phase diagram. The tin concentration of the high temperature $\mathrm{a}-\mathrm{Cu}$ phase produced at temperatures of $350^{\circ} \mathrm{C}$ and higher is higher than $6.2 \mathrm{at} \%$ and that of the low temperature $\mathrm{a}-\mathrm{Cu}$ phase produced at temperatures of $250^{\circ} \mathrm{C}$ and lower is lower than approximately $1.0 \mathrm{at} \%$. Thus, the tin concentration of the $\mathrm{a}-\mathrm{Cu}$ phase produced at high temperatures is higher than that of the $\mathrm{a}-\mathrm{Cu}$ phase produced at low temperatures. From this, it can be determined that the Gilt-Bronze Pensive Bodhisattva cast using the piece-mold casting method gradually cooled in a wide temperature range.

\subsection{Mould analysis results}

\subsubsection{Principal component analysis}

Table 4 shows the major component analysis result of the mould. The principal components of the interior and exterior of the rear head were $\mathrm{SiO}_{2}$ and $\mathrm{Al}_{2} \mathrm{O}_{3}$ but the components of $\mathrm{CaO}, \mathrm{FeO}, \mathrm{K}_{2} \mathrm{O}$ and $\mathrm{MgO}$ were also present. Similarly,

Table 4. Component analysis result of the mould

\begin{tabular}{|c|c|c|c|c|c|c|c|c|c|c|c|c|c|c|c|c|}
\hline \multirow{2}{*}{ No. } & \multirow{2}{*}{ Name } & \multicolumn{15}{|c|}{ Chemical composition (wt\%) } \\
\hline & & $\mathrm{SiO}_{2}$ & $\mathbf{A l}_{2} \mathbf{O}_{3}$ & $\mathrm{FeO}$ & $\mathrm{CaO}$ & $\mathbf{K}_{2} \mathrm{O}$ & MgO & $\mathrm{SO}_{3}$ & $\mathrm{TiO}_{2}$ & $\mathbf{P}_{2} \mathbf{O}_{5}$ & $\mathrm{Na}_{2} \mathrm{O}$ & MnO & $\mathrm{ZnO}$ & SrO & $\mathrm{ZrO}_{2}$ & $\mathrm{CuO}$ \\
\hline 1 & $\begin{array}{c}\text { The last } \\
\text { exterior layer } \\
\text { of the rear } \\
\text { head }\end{array}$ & 55.07 & 16.90 & 4.21 & 12.05 & 2.75 & 3.23 & 3.86 & 0.79 & 0.46 & 0.43 & 0.05 & 0.05 & 0.04 & 0.03 & 0.02 \\
\hline 2 & $\begin{array}{c}\text { Exterior layer } \\
\text { of the rear } \\
\text { head }\end{array}$ & 55.97 & 17.30 & 4.23 & 11.23 & 2.83 & 2.70 & 4.08 & 0.76 & 0.46 & 0.33 & 0.05 & 0.02 & 0.03 & 0.03 & 0.02 \\
\hline 3 & $\begin{array}{c}\text { Middle layer } \\
\text { of the rear } \\
\text { head }\end{array}$ & 54.86 & 17.20 & 4.21 & 12.25 & 2.74 & 2.96 & 3.96 & 0.83 & 0.46 & 0.35 & 0.06 & 0.02 & 0.04 & 0.03 & 0.02 \\
\hline 4 & \begin{tabular}{|c|} 
Interior layer \\
of the rear \\
head
\end{tabular} & 56.08 & 17.10 & 4.13 & 11.70 & 2.74 & 2.81 & 3.66 & 0.77 & 0.50 & 0.34 & 0.05 & 0.02 & 0.04 & 0.03 & 0.02 \\
\hline 5 & $\begin{array}{c}\text { The most } \\
\text { interior layer } \\
\text { of the rear } \\
\text { head }\end{array}$ & 67.30 & 16.90 & 3.78 & 3.40 & 2.93 & 1.05 & 2.98 & 0.76 & 0.46 & 0.29 & - & 0.02 & 0.02 & 0.03 & 0.02 \\
\hline 6 & $\begin{array}{l}\text { The last } \\
\text { exterior layer } \\
\text { of the kneel }\end{array}$ & 55.98 & 16.80 & 4.30 & 11.23 & 2.78 & 2.94 & 4.13 & 0.79 & 0.52 & 0.38 & 0.05 & 0.02 & 0.03 & 0.03 & 0.02 \\
\hline 7 & $\begin{array}{l}\text { Exterior layer } \\
\text { of the kneel }\end{array}$ & 55.70 & 17.10 & 4.20 & 11.68 & 2.79 & 2.83 & 3.93 & 0.78 & 0.47 & 0.33 & 0.04 & 0.02 & 0.04 & 0.03 & 0.02 \\
\hline 8 & $\begin{array}{l}\text { Middle layer } \\
\text { of the kneel }\end{array}$ & 52.59 & 15.90 & 4.30 & 15.13 & 2.56 & 3.71 & 4.12 & 0.77 & 0.47 & 0.27 & 0.06 & 0.02 & 0.04 & 0.03 & 0.02 \\
\hline 9 & $\begin{array}{l}\text { Interior layer } \\
\text { of the kneel }\end{array}$ & 67.90 & 16.40 & 3.72 & 3.64 & 2.88 & 1.02 & 2.66 & 0.76 & 0.43 & 0.36 & - & 0.02 & 0.02 & 0.03 & 0.02 \\
\hline 10 & $\begin{array}{l}\text { The most } \\
\text { interior layer } \\
\text { of the kneel }\end{array}$ & 68.90 & 16.60 & 3.92 & 2.38 & 3.03 & 0.84 & 2.55 & 0.78 & 0.47 & 0.26 & 0.03 & 0.05 & 0.01 & 0.03 & 0.08 \\
\hline
\end{tabular}


the principal components of the interior and exterior of the knee were $\mathrm{SiO}_{2}$ and $\mathrm{Al}_{2} \mathrm{O}_{3}$ but the components of $\mathrm{CaO}, \mathrm{FeO}$, $\mathrm{K}_{2} \mathrm{O}$, and $\mathrm{MgO}$ were also present. The component analysis results for the mould used for each part did not vary significantly within the error range so it was determined that the same materials were used in the fabrication.

\subsubsection{Chemical analysis}

XRD analysis was carried out to investigate the major chemical compounds composing the mould. Figure 10 shows the XRD analysis result for the mould, which revealed the detection of quartz, dolomite, and muscovite in the rear head and knee interior. The exteriors of the rear head and knee also resulted in the detection of large quantities of quartz along with dolomite and muscovite.

\subsubsection{Rear buttocks microstructure observation}

Figure 11 shows the stereoscopic microscope and SEM imaging on the rear buttocks microstructure. Large quartz are observed in the exterior while a large amount of smaller quartz are observed in the interior. Additionally, organic matter is observed. Table 5 shows the compositions of each structure using EDS. Number 1 shows unmelted mineral particles while numbers 2, 3, and 5 show fine quartz. Number 4 shows the base matrix.

\subsubsection{Pedestal Knee Microstructure Observation}

Figure 12 shows the stereoscopic microscope image of the pedestal knee microstructure. Large quartz are observed in the exterior while large quantities of smaller quartz are observed in the interior. Also, organic matter is observed. Figure 12 shows the SEM image of the detailed microstructure of the pedestal knee. Table 6 shows the compositions of each structure using EDS. Numbers 1 and 4 are quartz, numbers 2 and 5 are unmelted mineral particles, and number 3 is the base matrix.

Small polygonal particles are observed in the base matrix, and it was determined that the mould was fabricated by adding quartz and organic matter for structural stability, fire resistance, and air permeability.

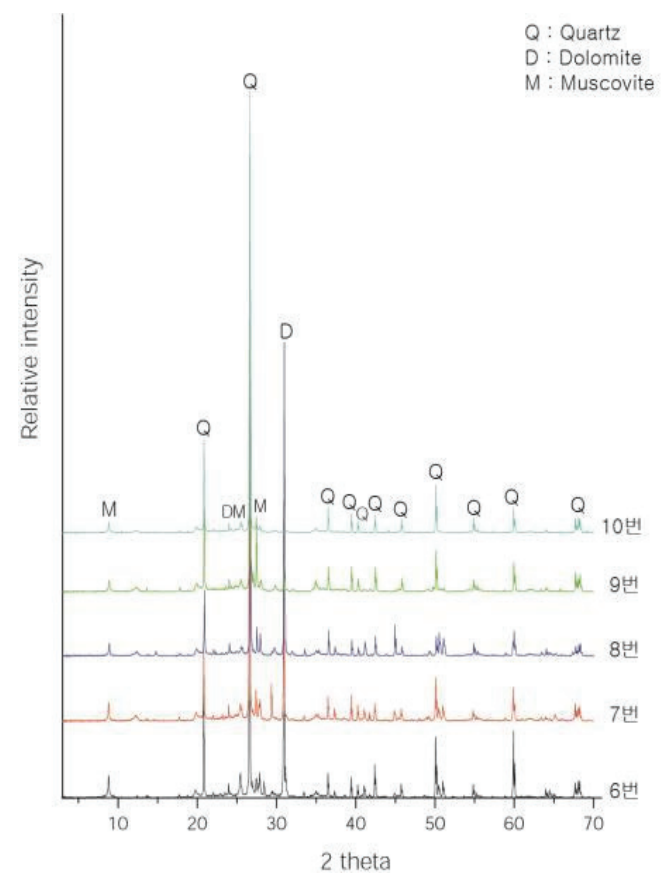

Figure 10. XRD analysis result of the mould (left: No. 3 the rear head, right: No. 4 knee interior). 


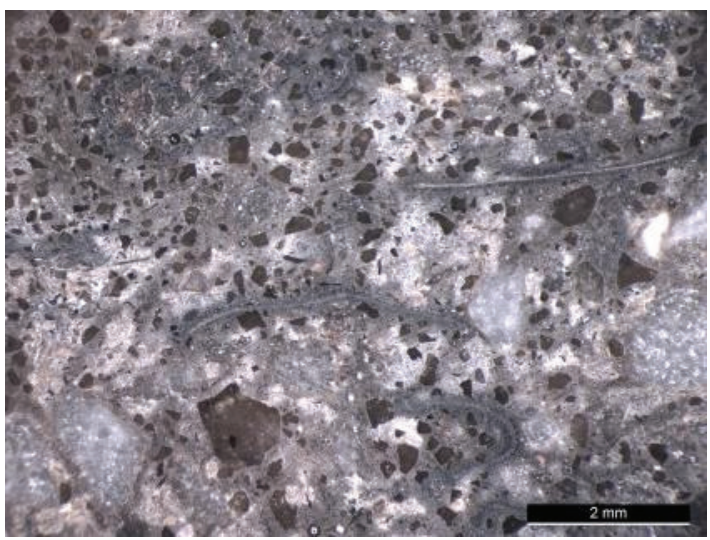

A

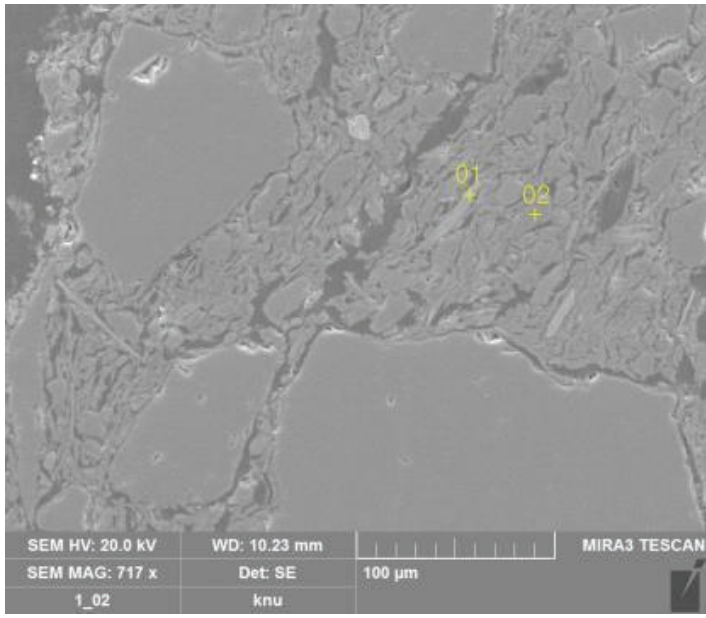

C

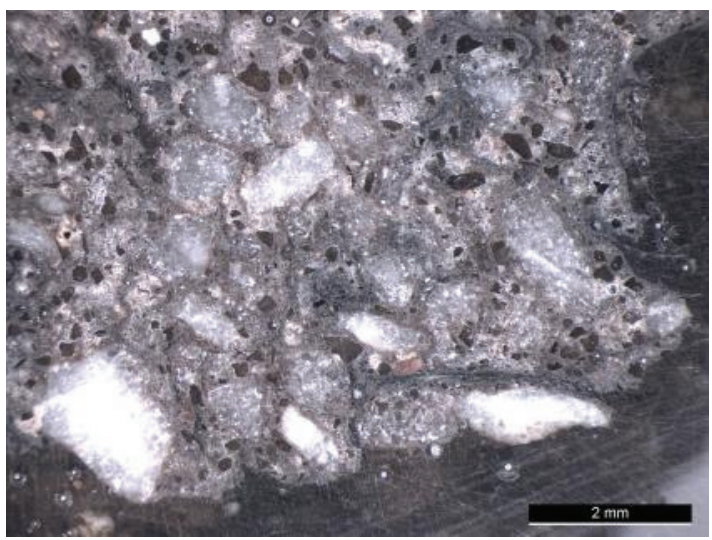

B

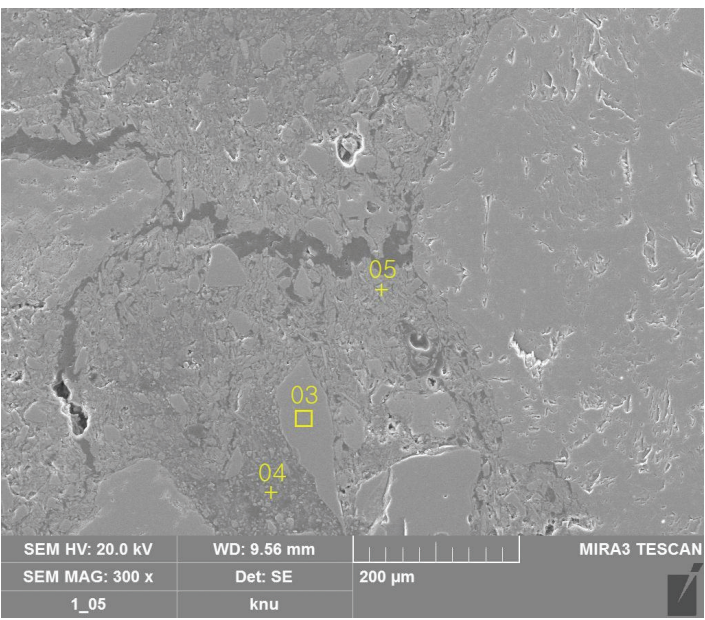

D

Figure 11. No.1 rear buttocks microstructure observation. (A) The stereoscopic microscope (x1.60) of the interior. (B) The stereoscopic microscope (x1.60) of the exterior. (C) SEM image of the interior. (D) SEM image of the exterior.

Table 5. EDS analysis result of No.1 rear buttocks (Unit: wt\%)

\begin{tabular}{c|c|c|c|c|c|c|c|c}
\hline \multirow{2}{*}{$\begin{array}{c}\text { Analysis } \\
\text { position }\end{array}$} & \multicolumn{9}{|c}{ Elements (wt\%) } \\
\cline { 2 - 10 } & $\mathbf{S i O}_{2}$ & $\mathrm{Al}_{2} \mathbf{O}_{3}$ & $\mathbf{C}$ & $\mathbf{C a O}$ & $\mathbf{M g O}$ & $\mathbf{K}_{2} \mathbf{O}$ & $\mathbf{F e O}$ & $\mathbf{C l}$ \\
\hline 1 & 40.61 & 31.56 & 17.17 & 2.25 & 1.10 & 6.41 & 0.89 & - \\
\hline 2 & 86.03 & - & 13.97 & - & - & - & - & - \\
\hline 3 & 91.61 & - & 8.39 & - & - & - & - & - \\
\hline 4 & 31.84 & 13.73 & 44.78 & 1.65 & 0.98 & 1.69 & 4.78 & 0.57 \\
\hline 5 & 84.70 & - & 15.30 & - & - & - & - & - \\
\hline
\end{tabular}




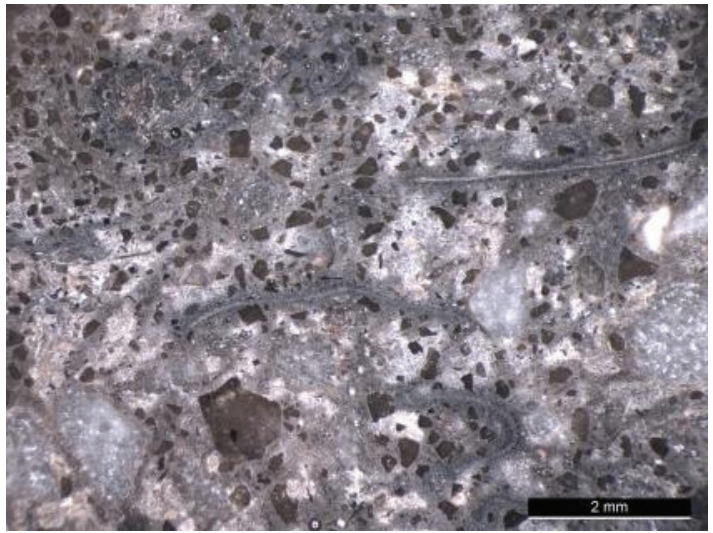

A

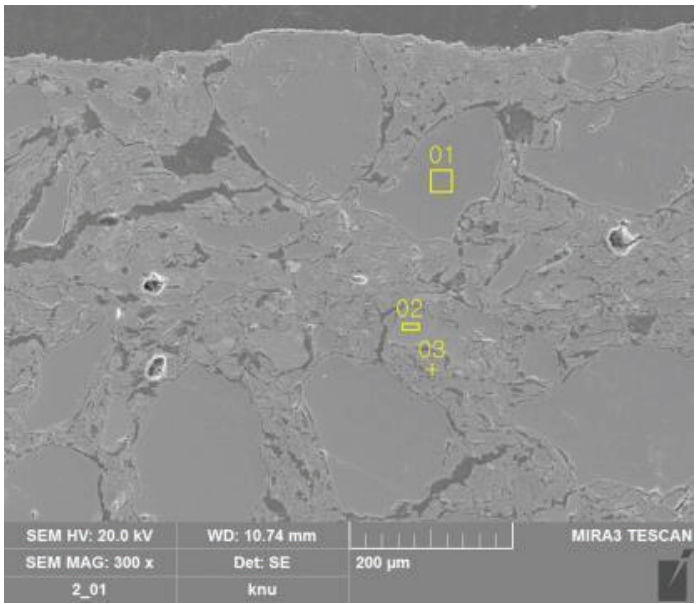

C

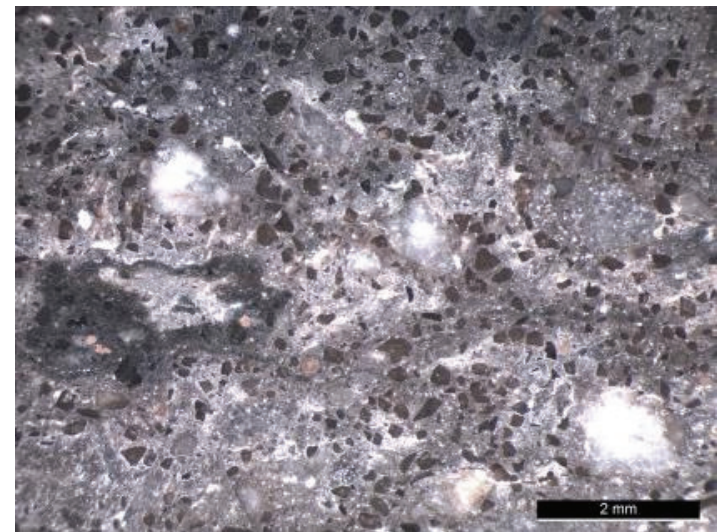

B

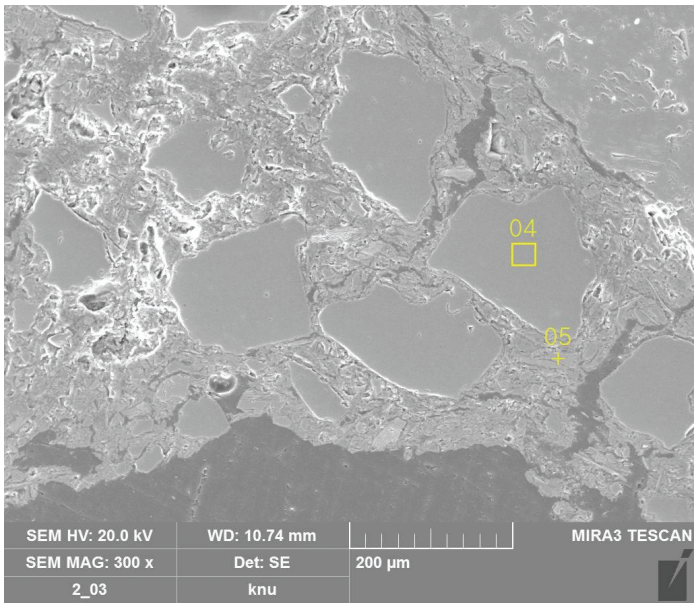

D

Figure 12. No. 2 Pedestal Knee Microstructure Observation. (A) The stereoscopic microscope (x1.60) of the interior. (B) The stereoscopic microscope (x1.60) of the exterior. (C) SEM image of the interior. (D) SEM image of the exterior.

Table 6. EDS analysis result of No. 2 Pedestal Knee (Unit: wt\%)

\begin{tabular}{|c|c|c|c|c|c|c|c|c|}
\hline \multirow{2}{*}{$\begin{array}{c}\text { Analysis } \\
\text { position }\end{array}$} & \multicolumn{8}{|c|}{ Elements (wt\%) } \\
\hline & $\mathrm{SiO}_{2}$ & $\mathrm{Al}_{2} \mathrm{O}_{3}$ & C & $\mathrm{CaO}$ & MgO & $\mathbf{K}_{2} \mathbf{O}$ & $\mathrm{FeO}$ & $\mathrm{Na}_{2} \mathrm{O}$ \\
\hline 1 & 93.01 & - & 6.99 & - & - & - & - & - \\
\hline 2 & 60.29 & 20.77 & 1.54 & - & - & 16.54 & - & 0.87 \\
\hline 3 & 39.02 & 28.95 & 22.33 & 0.55 & 0.89 & 2.31 & 5.06 & 0.89 \\
\hline 4 & 91.30 & - & 8.70 & - & - & - & - & - \\
\hline 5 & 57.39 & 19.40 & 2.90 & - & - & 20.32 & - & - \\
\hline
\end{tabular}




\section{CONCLUSION}

For the traditional casting and restoration technique research of the bronze Pensive Bodhisattva, ancient literatures on bronze alloy, casting, and processing technologies were investigated and preceding research materials regarding the traditional metallic casting techniques were collected. Also, in the case of metallic casting techniques, this study aimed to investigate the traditional metallic (copper) smelting method as well as casting and processing techniques that are dying out by restoring the systematic research process from smelting to cast fabrication, copper alloys, and casting.

Literature survey for the identification of traditional smelting and casting techniques was necessary and ancient literature provided fragmentary insight into copper alloy and smelting techniques, casting methods, cast fabrication, and casting records. The bronze Pensive Bodhisattva scaled down restoration experiment was carried out based on the smelting method, alloy and casting techniques, cast fabrication techniques, and casting techniques followed through the ancient literature review and survey.

Preliminary experimentation was conducted to present a systematic methodology for the traditional casting and restoration technologies of the bronze Pensive Bodhisattva. Utilizing preceding materials, the cast was made with piece-mold and molten metal was poured in followed by a series of refinements to successfully restore a $1 / 3$ scale model of the bronze Pensive Bodhisattva.

During the restoration experiment of the Gilt-Bronze Pensive Bodhisattva of $1 / 2$ scale model, the mould production went through the process of Reproduction Study using Piece-Mold Casting, the processes of mould mold fabrication, mould supplementation, and core fabrication were carried out. In the casting process, mould assembly, molten metal preparation, molten metal injection, mould disassembly, and polishing were conducted. However, the surface of the back is not even, so it seems necessary to conduct the experiment again in the future to solve this problem.

A scientific analysis of the restored Gilt-Bronze Pensive Bodhisattva showed that the typical cast was identified through the microstructure observation and that it gradually cooled down over a wide temperature range. Also, in the $\mathrm{Zn}$ component analyzed together, it appears that some of the components included in the added $\mathrm{Pb}$ were detected. As a result of the analysis of the mould, quartz is observed, and small polygon particles were observed at the base matrix. A large number of quartz were observed, indicating that quartz and organic materials were added to create moulds for structural stability, fire-resistance, and air permeability.

This study examined the traditional casting and restoration techniques of Gilt-Bronze Pensive Bodhisattva and conducted restoration studies based on our disappearing traditional casting techniques. For this, it was reviewed through traditional metal casting techniques, mould production techniques, casting and alloy standards. And this study can be used as a basic material for research on the traditional casting and restoration techniques of Gilt-Bronze Pensive Bodhisattva that have been incomplete. In particular, Pensive Bodhisattva is a relic of Korea's unique characteristics and is an important metal cultural asset for the study of traditional science history and ancient Buddhist sculpture history. And it is expected to design a systematic research process and secure accurate casting scientific technique data. In addition, the newly restored Pensive Bodhisattva is based on the traditional casting and processing technique of bronze and is expected to be used for exhibition and educational purposes.

\section{REFERENCES}

Min, B.C., 2016, Casting technique of gilt - bronze Pensive Bodhisattva Statues: Korean National treasures no. 78 and no. 83, National Museum of Korea, 146-167. (in Korean with English abstract)

National Museum of Korea, 2017, Scientific research on Gilt-bronze Pensive Bodhisattva of Korea \& Japan, National Museum of Korea, 85-87, 470-550.

Yun, Y.H., 2013, A study on the casting technology and restoration of bronze artifacts, Korea University, 13-43. (in Korean with English abstract)

Yun, Y.H., Cho, N.C., Doh, J.M., Yun, D.S., Park, H.G., Kim., S.C., Nam, S.Y. and Kang, Y.N.,, 2019, Study on Traditional Casting Technology and Restoration of Bronze(Gilt bronze) Pensive Bodhisattva statue, National Science Museum, 2-7.

Yun, Y.H., Cho, N.C. and Doh, J.M., 2020, Experimental research of lost-wax casting: Gilt-Bronze Pensive Bodhisattva. Journal of Conservation Science, 36(2), 123-142. (in Korean with English abstract) 